\title{
Radical segmentectomy as a potential alternative surgical treatment with curative intent in early-stage non-small cell lung cancer
}

\author{
Terumoto Koike, Tatsuya Goto, Seijiro Sato, Masanori Tsuchida \\ Division of Thoracic and Cardiovascular Surgery, Niigata University Graduate School of Medical and Dental Sciences, Niigata, Japan \\ Correspondence to: Terumoto Koike, MD, PhD. Division of Thoracic and Cardiovascular Surgery, Niigata University Graduate School of Medical and \\ Dental Sciences, 1-757 Asahimachi-dori, Chuo-ku, Niigata, Niigata 951-8510, Japan. Email: t-koike@med.niigata-u.ac.jp. \\ Comment on: Mimae T, Okada M. Are segmentectomy and lobectomy comparable in terms of curative intent for early stage non-small cell lung \\ cancer? Gen Thorac Cardiovasc Surg 2020;68:703-6.
}

Submitted Apr 05, 2020. Accepted for publication Apr 22, 2020.

doi: $10.21037 /$ jtd-20-1582

View this article at: http://dx.doi.org/10.21037/jtd-20-1582

Since the Lung Cancer Study Group (LCSG) reported the results of a prospective, randomized, and comparative trial of sublobar resection $v$ s. lobectomy for non-small cell lung cancer (NSCLC) measuring $\leq 3 \mathrm{~cm}$ in 1995 (1), lobectomy has been the standard surgical procedure for NSCLC, even for small tumors. In the LCSG study, a three-time higher locoregional recurrence rate was seen with relatively lower overall and cancer-specific survival in patients who underwent sublobar resection, including both segmentectomy and wedge resection, compared to those who underwent lobectomy. In the 2000s, some studies demonstrated favorable postoperative outcomes after segmentectomy in patients with early-stage NSCLC (2-5). These studies focused on relatively smaller tumors compared to those investigated in the LCSG study and focused solely on segmentectomy in sublobar resection surgeries. In a recently published review article, titled "Are segmentectomy and lobectomy comparable in terms of curative intent for early stage non-small cell lung cancer?" by Mimae et al. (6), the authors specifically referred to radical segmentectomy for early-stage NSCLC and discussed the possibility of segmentectomy as an alternative to lobectomy for the surgical treatment with curative intent for early-stage NSCLC.

\section{Difference between segmentectomy and wedge resection}

In the review article by Mimae et al. (6), the authors first discussed the extent of pulmonary resection in sublobar resection surgery. As mentioned above, the LCSG demonstrated a significantly higher locoregional recurrence rate with relatively lower postoperative survival in patients undergoing sublobar resection, compared to those undergoing lobectomies for clinical stage IA NSCLC (1). However, the LCSG study enrolled patients who underwent segmentectomy and wedge resection in the sublobar resection group; in fact, 40 of the 122 patients $(32.8 \%)$ in the sublobar resection group underwent wedge resection. It is considered that anatomic segmentectomy is a superior oncologic approach compared to nonanatomic wedge resection, and that segmentectomy has the theoretical advantage of a more radical resection. Anatomic segmentectomy achieves appropriate margins by reducing the technical limitations and involves wider resection of the draining lymphatics existing in intersegmental planes that are considered a source of residual cancer cells (7). Many previous studies about sublobar resection in early-stage NSCLC focused solely on segmentectomy, and favorable postoperative outcomes after segmentectomy have been reported (5-year overall survival rates of $87-90 \%, 10$-year overall survival rates of $81-84 \%$, and an overall recurrence rate of $17 \%$ ) (2-5). In fact, in our previous retrospective study involving patients with clinical stage IA NSCLC $(\leq 3 \mathrm{~cm})$ who underwent sublobar resection, wedge resection was identified as a significant independent risk factor for locoregional recurrence and poor disease-specific survival [hazard ratios (HRs) of 5.787 and 3.183 , respectively] 
compared to segmentectomy (8). Similar results were reported in the United States (9), and segmentectomy was associated with a significantly better overall (HR: 0.80) and lung cancer-specific survival (HR: 0.72) in patients with stage IA NSCLC who underwent sublobar resection. Mimae et al. mentioned in their review article (6) that anatomic segmentectomy involving lymph node dissection, but not wedge resection, allows hilar nodal dissection and a wider surgical margin. Although both segmentectomy and wedge resection are classified as sublobar resections, anatomic segmentectomy with systematic lymphadenectomy must be clearly differentiated from wedge resection and segmentectomy without lymphadenectomy. Moreover, it is considered that intentional radical segmentectomy and segmentectomy for lobectomy intolerable patients need to be independently discussed. Intentional radical segmentectomy should be compared with lobectomy for the curative intent treatment of early-stage NSCLC.

\section{Preoperative radiologic assessment of early- stage NSCLC for segmentectomy}

In the LCSG study, the enrolled patients were diagnosed with clinical T1N0 disease $(\leq 3 \mathrm{~cm})$ by posteroanterior and lateral chest roentgenogram, and computed tomography (CT) for detecting occult distant metastasis, such as the brain, lung, liver, and adrenal glands metastasis was not routinely performed (1). Thus, the disease stage might have been underestimated compared to the current preoperative staging, which is evaluated by high resolution $\mathrm{CT}$ and ${ }^{18} \mathrm{~F}$-fluorodeoxyglucose positron emission tomography/CT (FDG-PET/CT). Moreover, tumors that general thoracic surgeons often encounter in recent times, such as small tumors with ground glass opacity (GGO) components, might not have been included in the LCSG study. In the current TNM staging system (10), the solid component size is one of the factors determining the T-factor whereas a GGO component is not involved in tumor diameter and the T-factor. Because the solid component size reflects an extension of the invasive component size, oncological feature is considered more precisely defined in the 8 th, rather than in the previous versions of TNM classification (11). However, Mimae et al. mentioned in their review article (6) that the entire tumor size including the GGO component is more important for determining the surgical indication for segmentectomy in stage I NSCLC. The results of previous studies about sublobar resection (12-14) suggested that the entire tumor size $\leq 2 \mathrm{~cm}$ might be a good indication for sublobar resection, and the entire tumor size and tumor location on preoperative high resolution CT should be assessed to secure an appropriate surgical margin and to avoid local recurrence after segmentectomy. In fact, in our recent analysis of risk factors for the recurrence of earlystage NSCLC in patients who underwent anatomic segmentectomy (15), some patients with small solid component size developed surgical margin recurrence, despite having a lower overall risk of recurrence. Mimae et al. recommended lobectomy or more extended resections, including sleeve lobectomy, bi-lobectomy, and pneumonectomy even for small tumors that are difficult to secure an adequate margin by segmentectomy, such as centrally located tumors and those located around the root of the lobar bronchus.

Mimae et al. also referred to some preoperative radiologic parameters which are associated with the malignant potential of early-stage NSCLC $(16,17)$, such as the consolidation to tumor $(\mathrm{C} / \mathrm{T})$ ratio on $\mathrm{CT}$ and the maximum standardized uptake value (SUVmax) on FDG-PET/CT (6). The C/ $\mathrm{T}$ ratio is defined as the maximum solid component diameter divided by the maximum tumor diameter on high resolution CT (18). Since tumors with a high proportion of GGO components reflect a high proportion of noninvasive adenocarcinoma, a low $\mathrm{C} / \mathrm{T}$ ratio could indicate low malignant adenocarcinomas, such as adenocarcinoma in situ and minimally invasive adenocarcinoma (11). Many previous studies about intentional sublobar resection addressed small NSCLC with a low C/T ratio, and excellent postoperative survival was seen in patients with such tumors $(19,20)$. Although such less aggressive tumors are considered a good indication for sublobar resection, Mimae et al. suggested that small tumors with a low $\mathrm{C} / \mathrm{T}$ ratio are not suitable for a comparative prospective study of lobectomy $v s$. segmentectomy because these tumors can be cured even with wide-wedge resection (18).

The SUVmax of 1.5 on FDG-PET/CT was reported as a threshold to predict lymph node metastasis (16), and our previous study indicated a predictive effect of SUVmax $\geq 6.10$ on the pathological metastasis and involvement in clinical stage IA NSCLC (21). However, Mimae et al. suggested that currently, an SUVmax on FDG-PET/ CT cannot be relied on to decide the indication for segmentectomy for early-stage NSCLC. This is because FDG-PET/CT modalities continue to be evolving, thus improving the sensitivity (6). Moreover, the meaning of actual value of SUVmax differs between modalities, 
institutions, and generations.

\section{Preserved pulmonary function after segmentectomy}

Compared to lobectomy, segmentectomy has the theoretical advantage of preserving the postoperative pulmonary function because of the smaller extent of excised lung parenchyma. Although the LCSG study concluded that sublobar resection did not preserve the postoperative pulmonary function because the forced vital capacity (FVC) or maximum voluntary ventilation were not significantly better [but the forced expiratory volume in 1 second $\left(\mathrm{FEV}_{1}\right)$ was better] relative to sublobar resection (1), some previous studies, including our study, suggest significantly better preservation of $\mathrm{FVC}$ and $\mathrm{FEV}_{1}$ in patients who underwent segmentectomy than in those who underwent lobectomy $(14,22)$. Mimae et al. (6) also mentioned that although some segmentectomies create several intricate intersegmental planes and are considered a complex segmentectomy, both simple and complex segmentectomy may contribute to better postoperative pulmonary function than lobectomy for early-stage NSCLC patients (23).

\section{Radical segmentectomy as a potential alternative surgical treatment with curative intent in early-stage NSCLC}

In the review article by Mimae et al. (6), the authors discussed whether radical segmentectomy can be an alternative to lobectomy as a surgical treatment with curative intent for early-stage NSCLC patients. They stated that segmentectomy is more valuable than wedge resection in terms of an oncological perspective; thus, anatomic segmentectomy with lymph node dissection needs to be independently examined compared to lobectomy. Moreover, even in small NSCLC, the entire tumor size and tumor location on preoperative high resolution CT should be carefully assessed to secure an adequate surgical margin after segmentectomy, and other preoperative radiologic factors, such as $\mathrm{C} / \mathrm{T}$ ratio and SUVmax might be necessary to determine an indication for segmentectomy in the future. This is because segmentectomy will likely become the standard surgical procedure for early-stage NSCLC following the results of ongoing prospective, randomized trials of lobectomy $v s$. sublobar resection in patients with early-stage NSCLC, such as Cancer and Leukemia Group B 140503 (24) and Japan Clinical Oncology Group 0802/ West Japan Oncology Group 4607L (25). Thus, Mimae et al. concluded that general thoracic surgeons will need to master segmentectomy because the opportunity to encounter patients with small NSCLC who need surgical treatment continues to increase (6).

\section{Acknowledgments}

Funding: None.

\section{Footnote}

Provenance and Peer Review: This article was commissioned and reviewed by the Section Editor Dr. Laura Chiara Guglielmetti (Cantonal Hospital Winterthur, Kantonsspital Winterthur, Switzerland).

Conflicts of Interest: All authors have completed the ICMJE uniform disclosure form (available at http://dx.doi. org/10.21037/jtd-20-1582). The authors have no conflicts of interest to declare.

Ethical Statement: The authors are accountable for all aspects of the work in ensuring that questions related to the accuracy or integrity of any part of the work are appropriately investigated and resolved.

Open Access Statement: This is an Open Access article distributed in accordance with the Creative Commons Attribution-NonCommercial-NoDerivs 4.0 International License (CC BY-NC-ND 4.0), which permits the noncommercial replication and distribution of the article with the strict proviso that no changes or edits are made and the original work is properly cited (including links to both the formal publication through the relevant DOI and the license). See: https://creativecommons.org/licenses/by-nc-nd/4.0/.

\section{References}

1. Ginsberg RJ, Rubinstein LV. Randomized trial of lobectomy versus limited resection for T1 N0 non-small cell lung cancer. Lung Cancer Study Group. Ann Thorac Surg 1995;60:615-22; discussion 622-3.

2. Okada M, Yoshikawa K, Hatta T, et al. Is segmentectomy with lymph node assessment an alternative to lobectomy 
for non-small cell lung cancer of $2 \mathrm{~cm}$ or smaller? Ann Thorac Surg 2001;71:956-60; discussion 961.

3. Schuchert MJ, Pettiford BL, Keeley S, et al. Anatomic segmentectomy in the treatment of stage I non-small cell lung cancer. Ann Thorac Surg 2007;84:926-32; discussion 932-3.

4. Koike T, Koike T, Yamato Y, et al. Prognostic predictors in non-small cell lung cancer patients undergoing intentional segmentectomy. Ann Thorac Surg 2012;93:1788-94.

5. Nomori H, Mori T, Shiraishi A, et al. Long-Term Prognosis After Segmentectomy for cT1 N0 M0 Non-Small Cell Lung Cancer. Ann Thorac Surg 2019;107:1500-6.

6. Mimae T, Okada M. Are segmentectomy and lobectomy comparable in terms of curative intent for early stage non-small cell lung cancer? Gen Thorac Cardiovasc Surg 2020;68:703-6.

7. Blasberg JD, Pass HI, Donington JS. Sublobar resection: a movement from the Lung Cancer Study Group. J Thorac Oncol 2010;5:1583-93.

8. Koike T, Koike T, Yoshiya K, et al. Risk factor analysis of locoregional recurrence after sublobar resection in patients with clinical stage IA non-small cell lung cancer. J Thorac Cardiovasc Surg 2013;146:372-8.

9. Smith CB, Swanson SJ, Mhango G, et al. Survival after segmentectomy and wedge resection in stage I non-smallcell lung cancer. J Thorac Oncol 2013;8:73-8.

10. Goldstraw P, Chansky K, Crowley J, et al. The IASLC Lung Cancer Staging Project: Proposals for Revision of the TNM Stage Groupings in the Forthcoming (Eighth) Edition of the TNM Classification for Lung Cancer. J Thorac Oncol 2016;11:39-51.

11. Lee KH, Goo JM, Park SJ, et al. Correlation between the size of the solid component on thin-section CT and the invasive component on pathology in small lung adenocarcinomas manifesting as ground-glass nodules. J Thorac Oncol 2014;9:74-82.

12. Koike T, Yamato Y, Yoshiya K, et al. Intentional limited pulmonary resection for peripheral T1 N0 M0 small-sized lung cancer. J Thorac Cardiovasc Surg 2003;125:924-8.

13. Okada M, Koike T, Higashiyama M, et al. Radical sublobar resection for small-sized non-small cell lung cancer: a multicenter study. J Thorac Cardiovasc Surg 2006;132:769-75.
14. Koike T, Koike T, Sato S, et al. Lobectomy and limited resection in small-sized peripheral non-small cell lung cancer. J Thorac Dis 2016;8:3265-74.

15. Koike T, Nakamura A, Shimizu Y, et al. Characteristics and risk factors of recurrence in clinical stage I non-small cell lung cancer patients undergoing anatomic segmentectomy. Gen Thorac Cardiovasc Surg 2020;68:1011-7.

16. Tsutani Y, Miyata Y, Nakayama H, et al. Prediction of pathologic node-negative clinical stage IA lung adenocarcinoma for optimal candidates undergoing sublobar resection. J Thorac Cardiovasc Surg 2012;144:1365-71.

17. Tsutani $Y$, Miyata $Y$, Nakayama H, et al. Appropriate sublobar resection choice for ground glass opacitydominant clinical stage IA lung adenocarcinoma: wedge resection or segmentectomy. Chest 2014;145:66-71.

18. Suzuki K, Koike T, Asakawa T, et al. A prospective radiological study of thin-section computed tomography to predict pathological noninvasiveness in peripheral clinical IA lung cancer (Japan Clinical Oncology Group 0201). J Thorac Oncol 2011;6:751-6.

19. Koike T, Togashi K, Shirato T, et al. Limited resection for noninvasive bronchioloalveolar carcinoma diagnosed by intraoperative pathologic examination. Ann Thorac Surg 2009;88:1106-11.

20. Sagawa M, Oizumi H, Suzuki H, et al. A prospective 5 -year follow-up study after limited resection for lung cancer with ground-glass opacity. Eur J Cardiothorac Surg 2018;53:849-56.

21. Koike T, Shimizu Y, Goto T, et al. The Maximum Standardized Uptake Values on Positron Emission Tomography Predict Pathological Characteristics of NonSmall Cell Lung Cancer. Journal of Thoracic Oncology 2019;14:S548-S9.

22. Harada H, Okada M, Sakamoto T, et al. Functional advantage after radical segmentectomy versus lobectomy for lung cancer. Ann Thorac Surg 2005;80:2041-5.

23. Handa Y, Tsutani Y, Mimae T, et al. Surgical Outcomes of Complex Versus Simple Segmentectomy for Stage I Non-Small Cell Lung Cancer. Ann Thorac Surg 2019;107:1032-9.

24. National Institutes of Health. National Cancer Institute. CALGB-140503. Phase III Randomized Study of Lobectomy Versus Sublobar Resection in Patients With Small Peripheral Stage IA Non-Small Cell Lung Cancer. http://www.cancer.gov/clinicaltrials/CALGB-140503. 
Accessed: Mar 16, 2010.

25. Nakamura K, Saji H, Nakajima R, et al. A phase III randomized trial of lobectomy versus limited resection for small-sized peripheral non-small cell lung cancer (JCOG0802/WJOG4607L). Jpn J Clin Oncol 2010;40:271-4.

Cite this article as: Koike T, Goto T, Sato S, Tsuchida M. Radical segmentectomy as a potential alternative surgical treatment with curative intent in early-stage non-small cell lung cancer. J Thorac Dis 2020;12(10):6115-6119. doi: 10.21037/jtd-201582 